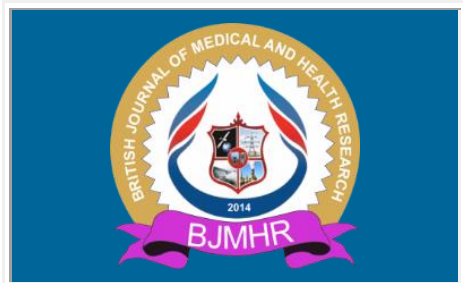

\title{
BJMHR
}

British Journal of Medical and Health Research

Journal home page: www.bjmhr.com

\section{Clinical Characteristics and Outcomes of 217 Kidney Transplantation Recipients Hospitalized with COVID-19: A Systematic Review}

Yongyi Shi ${ }^{1}$, , Shoufu Tian ${ }^{2}$

1 The First Clinical Medical School of Soochow University

2 The Department of Internal Medicine, the First Affiliated Hospital of Soochow University

\section{ABSTRACT}

Immunosuppressed kidney transplant recipients may have increased risk of causing severe disease during hospitalization of COVID-19. We conducted this review for better understanding the clinical characteristics and outcomes of this population. A literature search was undertaken to identify the studies which reported outcomes of kidney transplant recipients hospitalized with COVID-19 by searching MEDLINE, EMBASE, Web of Science and Google Scholar from January 1, 2019 to July 1, 2020. 38 studies reporting 217 KTR hospitalized with COVID-19 were included in the current study. All patients experienced fever, cough or dyspnea before hospitalization. $52.6 \%$ of recipients were classified as severe patients. The mortality of overall patients and discharged patients including those discharged alive and dead was $20.3 \%$ and $30.8 \%$, respectively. Among discharged patients, $53.3 \%$ of those admitted to ICU, $73.3 \%$ requiring invasive ventilation and 38.5\% receiving non-invasive ventilation died. $47.3 \%$ of in-hospital KTR developed AKI. Among the severe patients who developed AKI, $32.1 \%$ requiring renal replacement therapy during hospitalization. In conclusion, immunosuppressed kidney transplant recipients hospitalized with COVID-19 are at higher risk of developing severe disease $(53.3 \%)$ at a relatively young age and have higher mortality $(30.8 \%)$ and higher prevalence of acute kidney injury $(47.3 \%)$ compared to the general population with COVDI-19.

Keywords: Acute kidney injury; COVID-19; mortality; SARS-CoV-2; systematic review; transplantation

Please cite this article as: Shi Y et al., Clinical Characteristics and Outcomes of 217 Kidney

Transplantation Recipients Hospitalized with COVID-19: A Systematic Review. British Journal of Medical and Health Research 2020. 


\section{INTRODUCTION}

The coronavirus disease 2019 (COVID-19) outbreak caused by the severe acute respiratory syndrome coronavirus 2 (SARS-CoV-2) has become a global pandemic over the past few months with the number of global confirmed COVID-19 cases exceeding twelve million as of 10 July, $2020^{1}$. Although most individuals with COVID-19 present with mild symptoms, such as fever and dry cough, and are able to recover without any treatment ${ }^{2}$, some patients develop severe complications including sepsis, respiratory failure, acute kidney injury(AKI) and multi organ failure and even $\operatorname{die}^{3}$.

There is no consensus on to what extent immunosuppression can alter the clinical presentation, courses and outcomes of solid organ transplant recipients with COVID-19. Immunosuppressed patients may experience prolonged viral shedding time ${ }^{4}$ and virus-induced complications ${ }^{5}$. On the other hand, immunosuppressive therapy may provide transplant recipients with some protective effect by suppressing the hyperactive immune response to virus and preventing the cytokine release syndrome $(\mathrm{CRS})^{6}$ which is associated with the acute respiratory distress syndrome (ARDS) and respiratory failure ${ }^{7}$, the leading causes of death in patients with COVID- $19^{8}$.

Kidney transplant recipients (KTR) are the largest population amongst solid organ transplant patients $^{9}$ who are potentially vulnerable during the pandemic of COVID-19. However, only a handful of case reports, series and cohort studies with small sample size and diverse results exist in the current literature to explore the clinical features and outcomes of hospitalized COVID-19 positive KTR. Thus, we performed this systematic review to synthesize data for better understanding clinical characteristics, the prevalence of acute kidney injury and outcomes of this population.

\section{MATERIALS AND METHOD}

We conducted the review according to the PRISMA (Preferred Reporting Items for Systematic reviews and Meta-Analyses) guidelines ${ }^{10}$.

\section{Data Sources and Searches}

A comprehensive literature search was undertaken to identify the studies which reported clinical characteristics and outcomes of hospitalized kidney transplant recipients infected with COVID-19 by using 4 databases including MEDLINE, EMBASE, Web of Science and Google Scholar from January 1, 2019 to July 1, 2020. We used the combinations of the following search terms: COVID-19 OR coronavirus OR SARS-CoV-2 OR 2019-nCoV AND kidney transplantation. A hand search was also performed by checking the reference lists of the relevant studies identified through the above method and key journals regarding kidney diseases. 


\section{Eligibility Criteria}

The studies were included if they met the following inclusion criteria: (1) the studies reported clinical characteristics and outcomes of kidney transplant recipients diagnosed with COVID19, (2) published on peer-reviewed journals between December 1, 2019 and July 1, 2020, (3) written in English. Exclusion criteria for cases were as follows: (1) the patient who accepted non-kidney solid organ transplant, (2) repeated cases, (3) the patients under 18 years of age, (4) the studies not reporting clinical outcomes, (5) the patients who were not hospitalized.

\section{Study Selection and Data Extraction}

Two authors (YS and ST) independently performed study selection, evaluation of methodological quality and data abstraction with disagreement resolved by consensus discussion between them. Ineligible studies were excluded based on reviewing their titles, abstracts and full text of the studies.

The data collected from the eligible studies includes first author, country, publication status, age, sex, time from transplant, comorbidities, symptoms before admission, highest values of inflammatory biomarkers, creatinine and lowest values of lymphocyte count and estimated glomerular filtration Rate (eGFR), AKI, clinical courses and outcomes of the individual patients.

\section{Quality Assessment}

The CARE (CAse REport) guidelines ${ }^{11}$ including 8 items was applied to evaluate the methodological quality of the included studies in this systematic review. We classified studies as low quality if they have a quality score of 1-3, moderate quality if 4-6 and high quality if 78 .

\section{Data Synthesis and Statistical Analyses}

Different units for the same laboratory result were converted into a same unit for analysis. Statistical analysis was conducted using STATA version 14.2 software, with continuous variables demonstrated with mean \pm standard deviation $(\mathrm{SD})$, median, range and interquartile range (IQR) and categorical variables expressed as number of cases and percentages.

Based on the adjustment of the classification criteria for COVID-19 12 , we stratified the included patients by their disease severity. Those were classified as severe if they were reported to be admitted to ICU, required mechanical ventilation (MV) including invasive ventilation (IV) and non-invasive ventilation (NIV) or experienced severe COVID-19 complications including sepsis, respiratory failure and other organ failure. The remaining patients were classified as non-severe. The extracted data were compared between the severe and non-severe groups and between those who died and those discharged alive. Also, the mortality of different countries and age groups was analyzed. AKI is defined according to the KDIGO criteria ${ }^{13}$. The outcome of AKI was classified as resolved if serum creatinine return to within 1.5 times 
baseline and is less than $0.3 \mathrm{mg} / \mathrm{dl}(26.5 \mathrm{mmol} / \mathrm{l})$ increase from baseline and ongoing if serum creatinine does not return to that range.

\section{RESULTS AND DISCUSSION}

\section{Eligible Studies}

A total of 392 studies were screened and finally, 38 peer-reviewed articles from nine countries were included ${ }^{4,14-50}$ (figure 1). The methodological quality of each study was evaluated and summarized, suggesting the majority of the included studies show moderate to high quality. 6 studies rank as low quality, 20 as moderate quality and 12 as high quality according the CARE guideline.

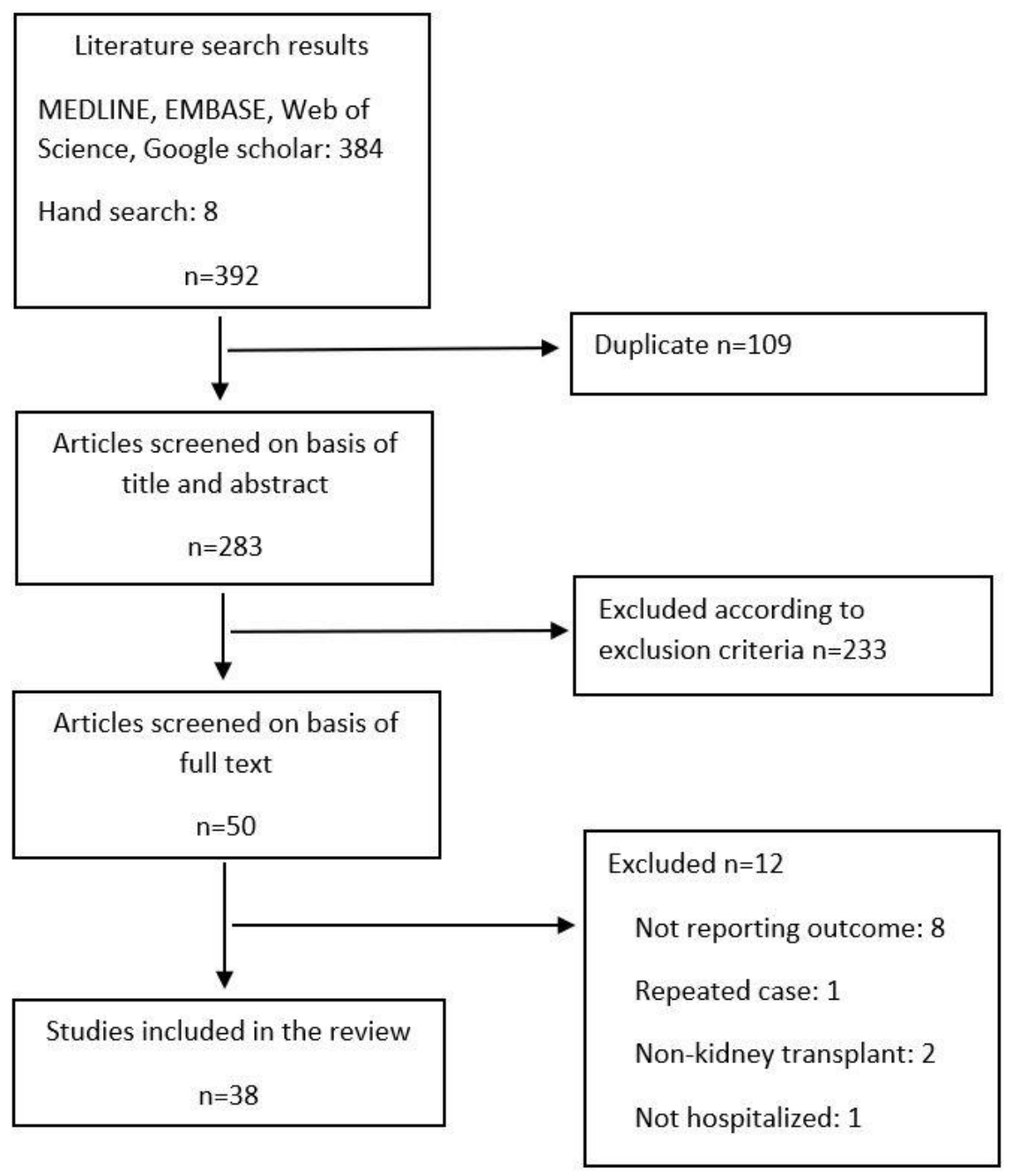

Figure 1: Literature search flow diagram

\section{Demography and Comorbidities}

217 hospitalized COVID-19 positive kidney transplant recipients (median age, 54 years old; range, 21-80 years old) were included for analysis (table 1). 52.6\% of patients were classified into the severe group. The majority patients $(74 \%)$ were male and the proportions of male patients in the non-severe and severe groups was $80 \%$ and $71 \%$, respectively. Male KTR are more likely to be admitted to hospital, but there is no significant difference in mortality between 
male and female population in this review. The median age (59 vs 50 years) and the median time from transplant ( 8.3 vs 4.5 years) of the severe patients was larger compared with those non-severe (table 1).

Among 109 KTR, 80 (73.4\%) reported at least one comorbidity. Hypertension (56.9\%), diabetes (27.5.0\%), cardiovascular disease (CVD) (17.4\%) and overweight or obesity (4.6\%) are the most prevalent comorbidities (table 1). The severe group had a higher proportion of hypertension (66.7\% vs $56.5 \%)$ and cardiovascular disease (21.6\% vs $15.2 \%)$ than the nonsevere group, but the prevalence of diabetes was similar between the two groups.

\section{Clinical Presentation and Laboratory Results}

All patients experienced at least one of the following three common COVID-19 symptoms: fever, cough or dyspnea. Symptoms started mean 7 days before hospitalization (table 1). Fever $(86.5 \%)$ is the commonest symptom for KTR before admission in this review, follow by cough (71.2\%), dyspnea (49.0\%), fatigue (26\%), and gastrointestinal (GI) symptoms (23.1\%) such as diarrhea or vomiting, and myalgia (19.2\%).

The mean values of the highest IL-6, CRP, procalcitonin, serum ferritin, D-dimer and serum creatinine and the lowest lymphocyte count and eGFR during hospitalization have significantly exceeded clinical normal ranges (table 1). These laboratory results were even worse in the severe patients than in the non-severe patients.

\section{Clinical Outcomes}

We found the mortality of KTR with COVID-19 requiring hospitalization is high. The overall mortality is $20.3 \%$ and the mortality is $30.8 \%$ among those discharged alive and dead (table 2). The mortality between different countries ranging from $10.5 \%$ in China to $69.2 \%$ in Iran has been noted (table 3 ). The mortality rate by 10 -year age intervals was demonstrated in the table 4 and it was noted that $41.4 \%$ of those who died were less than 60 years of age.

The mean follow up days from diagnosis of COVID-19 was 24 (table 2). For those who needed NIV or IV, the mean days from diagnosis to ventilation was 6 days. Among 51 severe patients, 15 were discharged, 19 died and 17 remained in hospital. However, none of patients in the nonsevere group died at the end of follow up.

Furthermore, $47.3 \%$ of KTR with COVID-19 develop acute kidney injury during hospitalization (table 5). We found severe patients are more likely to experience AKI (54.9\% vs $39.1 \%)$, less likely to resolve it $(10.7 \%$ vs $77.8 \%)$ and more frequently require renal replacement therapy ( $32.1 \%$ vs $5.6 \%$ ) compared to non-severe patients. 
Table 1: Demography, Comorbidities, Symptoms and Laboratory Results of In-hospital KTR with COVID-19

\begin{tabular}{|c|c|c|c|}
\hline & Total & Non-severe & Severe \\
\hline Total N & 217 & 46 & 51 \\
\hline \multicolumn{4}{|l|}{ Age } \\
\hline $\mathrm{N}$ & 124 & 46 & 51 \\
\hline Median (IQR) [range], y & $\begin{array}{l}54(44.5,65)[21, \\
80]\end{array}$ & $\begin{array}{l}50(38,61) \\
{[24,80]}\end{array}$ & $59(50,67)[32,80]$ \\
\hline \multicolumn{4}{|l|}{ Sex } \\
\hline Male, N (\%) & $92(74)$ & $37(80)$ & $36(71)$ \\
\hline Female, N (\%) & $32(26)$ & $9(20)$ & $15(29)$ \\
\hline \multicolumn{4}{|l|}{ Time from transplant, } \\
\hline $\mathrm{N}$ & 112 & 38 & 47 \\
\hline Median (IQR) [range], y & $\begin{array}{l}7.0(3.0,13.5)[0, \\
30.1]\end{array}$ & $\begin{array}{l}4.5(2.5,12.0) \\
{[0.3,30.1]}\end{array}$ & $\begin{array}{l}8.3(2.7,14.7)[0 \\
23.0]\end{array}$ \\
\hline $\begin{array}{l}\text { Time from symptom onset to diagnosis, } \\
\text { mean } \pm \mathrm{SD}, \mathrm{d}(\mathrm{N})\end{array}$ & $7 \pm 5(46)$ & $8 \pm 6(30)$ & $6 \pm 5(16)$ \\
\hline $\begin{array}{l}\text { Time from symptom onset to admission, } \\
\text { mean } \pm \mathrm{SD}, \mathrm{d}(\mathrm{N})\end{array}$ & $6 \pm 6(66)$ & $7 \pm 7(31)$ & $5 \pm 3(20)$ \\
\hline \multicolumn{4}{|l|}{ Comorbidities, $\mathrm{N}(\%)$} \\
\hline $\mathrm{N}$ & 109 & 46 & 51 \\
\hline $\mathrm{N}$ of comorbidities, mean $\pm \mathrm{SD}$ & $1.3 \pm 1.0$ & $1.2 \pm 1.1$ & $1.5 \pm 1.0$ \\
\hline Hypertension & $62(56.9)$ & $26(56.5)$ & $34(66.7)$ \\
\hline Diabetes & $30(27.5)$ & $15(32.6)$ & $15(29.4)$ \\
\hline CVD & $19(17.4)$ & $7(15.2)$ & $11(21.6)$ \\
\hline Overweight or obesity & $5(4.6)$ & $2(4.3)$ & $3(5.9)$ \\
\hline HCV infection & $4(3.7)$ & $0(0)$ & $4(7.8)$ \\
\hline Chronic respiratory disease & $3(2.8)$ & $0(0)$ & $2(3.9)$ \\
\hline \multicolumn{4}{|l|}{ Symptoms, N (\%) } \\
\hline $\mathrm{N}$ & 104 & 40 & 37 \\
\hline Fever & $90(86.5)$ & $35(87.5)$ & $32(86.5)$ \\
\hline Cough & $74(71.2)$ & $30(75.0)$ & $26(70.3)$ \\
\hline Dyspnea & $51(49.0)$ & $16(40.0)$ & $26(70.3)$ \\
\hline Fatigue & $27(26.0)$ & $17(42.5)$ & $7(18.9)$ \\
\hline Gastrointestinal symptoms & $24(23.1)$ & $8(20.0)$ & $9(24.3)$ \\
\hline Myalgia & $20(19.2)$ & $9(22.5)$ & $7(18.9)$ \\
\hline Rhinorrhea & $7(6.7)$ & $5(12.5)$ & $2(5.4)$ \\
\hline Chest pain or tightness & $6(5.8)$ & $3(7.5)$ & $3(8.1)$ \\
\hline Sore throat & $2(1.9)$ & $1(2.5)$ & $1(2.7)$ \\
\hline Anosmia, dysgeusia & $2(1.9)$ & $2(5.0)$ & $0(0)$ \\
\hline Loss of appetite & $2(1.9)$ & $1(2.5)$ & $1(2.7)$ \\
\hline Headache & $1(1.0)$ & $0(0)$ & $1(2.7)$ \\
\hline Hemoptysis & $1(1.0)$ & $0(0)$ & $0(0)$ \\
\hline \multicolumn{4}{|l|}{ Laboratory results, mean $\pm \mathrm{SD}(\mathrm{N})$} \\
\hline Lymphocyte count ${ }^{\mathrm{a}}, \times 10^{9} / 1$ & $0.68 \pm 0.40(85)$ & $0.72 \pm 0.38(33)$ & $0.55 \pm 0.37(28)$ \\
\hline $\mathrm{IL}^{\mathrm{b}} \mathrm{b}^{\mathrm{b}}, \mathrm{pg} / \mathrm{ml}$ & $339 \pm 967(25)$ & $197 \pm 244(7)$ & $1101 \pm 1864$ \\
\hline $\mathrm{CRP}^{\mathrm{b}}, \mathrm{mg} / \mathrm{l}$ & $94 \pm 85(72)$ & $79 \pm 87(25)$ & $138 \pm 88(22)$ \\
\hline Procalcitonin $^{\mathrm{b}}, \mathrm{ng} / \mathrm{ml}$ & $2.82 \pm 6.13(29)$ & $0.95 \pm 2.01(6)$ & $2.97 \pm 7.45(10)$ \\
\hline Serum ferritin ${ }^{\mathrm{b}}, \mathrm{ng} / \mathrm{ml}$ & $3038 \pm 9376(30)$ & $2471 \pm 2793(6)$ & $5699 \pm 14623(12)$ \\
\hline D-dimer ${ }^{b}, \mathrm{mg} / \mathrm{l}$ & $3.51 \pm 5.45(21)$ & $1.13 \pm 0.64(9)$ & $5.30 \pm 6.75(12)$ \\
\hline Creatinine $^{\mathrm{b}}, \mathrm{mg} / \mathrm{dl}$ & $2.56 \pm 1.64(87)$ & $2.23 \pm 1.79(39)$ & $3.00 \pm 1.56(36)$ \\
\hline $\mathrm{eGFR}^{\mathrm{a}}, \mathrm{ml} / \mathrm{min}$ per $1.73 \mathrm{~m}^{2}$ & $37 \pm 18(29)$ & $44 \pm 22(13)$ & $31 \pm 13(16)$ \\
\hline
\end{tabular}


Abbreviations: COVID-19, coronavirus disease 2019; CRP, C-reactive protein; CVD, cardiovascular disease; eGFR, estimated glomerular filtration rate; $\mathrm{HCV}$, hepatitis $\mathrm{C}$ virus; KTR, kidney transplant recipients;

${ }^{a}$ The highest value of the laboratory result reported by the study was collected.

$\mathrm{b}$ The lowest value of the laboratory result reported by the study was collected.

Table 2: Outcome and Mortality of In-hospital KTR with COVID-19

\begin{tabular}{llllll}
\hline & Total, N & $\begin{array}{l}\text { Died, } \\
\text { N }\end{array}$ & $\begin{array}{l}\text { Discharged } \\
\text { alive, }\end{array}$ & $\begin{array}{l}\text { In hospital, } \\
\mathbf{N}\end{array}$ & $\begin{array}{l}\text { Mortality of those } \\
\text { discharged (\%) }\end{array}$ \\
\hline N & 217 & 44 & 99 & 74 & 30.8 \\
Age, Median & $54(44.5$, & $63(57$, & $49(36,61)$ & $54(47,65)$ & N/A \\
(IQR), y & $65)$ & $70)$ & & & \\
Sex & & & & 28 & 34.4 \\
Male & 92 & 22 & 42 & 10 & 31.8 \\
Female & 32 & 7 & 15 & 16 & 0 \\
Non-severe & 46 & 0 & 30 & 17 & 55.9 \\
Severe & 51 & 19 & 15 & 6 & 53.3 \\
ICU & 21 & 8 & 7 & 16 & 57.1 \\
MV & 44 & 16 & 12 & 8 & 38.5 \\
NIV & 21 & 5 & 8 & 8 & 73.3 \\
IV & 23 & 11 & 4 & 19 & 32.4 \\
AKI & 53 & 11 & 23 & 19 & 25.0 \\
Those without AKI & 60 & 10 & 30 & 8 & 100 \\
RRT & 12 & 4 & 0 & $22 \pm 11(13)$ & N/A \\
LOS, mean \pm SD & $20 \pm 12$ & $15 \pm$ & $20 \pm 12(33)$ & & \\
(N) & $(50)$ & $15(4)$ & & $22 \pm 11(13)$ & N/A \\
Length of follow & $24 \pm 14$ & $15 \pm$ & $26 \pm 14(35)$ & & \\
up, mean \pm SD (N) & $(56)$ & $10(8)$ & & & \\
\hline
\end{tabular}

Abbreviations: AKI, acute kidney injury; COVID-19, coronavirus disease 2019; ICU, intensive care unit; IV, invasive ventilation; KTR, kidney transplant recipients; LOS, length of stay; MV, mechanical ventilation; NIV, non-invasive ventilation; RRT, renal replacement therapy.

Table 3: Mortality of discharged KTR with COVID-19 in Different Countries

\begin{tabular}{llllll}
\hline & China & Iran & The USA & Italy & Spain \\
\hline Outcome & & & & & \\
$\mathrm{N}$ & 19 & 13 & 69 & 20 & 16 \\
Died, N & 2 & 9 & 14 & 10 & 8 \\
Mortality of those discharged (\%) & 10.5 & 69.2 & 20.3 & 50.0 & 50.0 \\
\hline
\end{tabular}

Abbreviations: COVID-19, coronavirus disease 2019; KTR, kidney transplant recipients.

Table 4: Mortality Disposition by 10-Year Age Intervals of In-hospital KTR with COVID-19

\begin{tabular}{llll}
\hline Age intervals, $\mathbf{y}$ & Total, $\mathbf{N}$ & Died, $\mathbf{N}$ & Mortality of those discharged (\%) \\
\hline $20-29$ & 7 & 0 & 0 \\
$30-39$ & 14 & 2 & 14.3 \\
$40-49$ & 13 & 2 & 15.4 \\
$50-59$ & 20 & 8 & 40.0 \\
$60-69$ & 16 & 9 & 56.3 \\
$70-79$ & 15 & 8 & 53.3 \\
\hline
\end{tabular}




\begin{tabular}{llll}
\hline $80-89$ & 1 & 0 & 0
\end{tabular}

Abbreviations: COVID-19, coronavirus disease 2019; KTR, kidney transplant recipients.

Table 5: Prevalence and Outcomes of Acute Kidney Injury of In-hospital KTR with COVID-19

\begin{tabular}{lccc}
\hline & Total & Non-severe & Severe \\
\hline $\mathrm{N}$ & 112 & 46 & 51 \\
AKI, N (\%) & $53(47.3)$ & $18(39.1)$ & $28(54.9)$ \\
Outcome of AKI & & & \\
$\mathrm{N}$ & 53 & 18 & 28 \\
Resolved $^{\mathrm{a}}$ & $18(34.0)$ & $14(77.8)$ & $3(10.7)$ \\
Ongoing $^{\mathrm{a}}$ & $24(45.3)$ & $3(16.7)$ & $16(57.1)$ \\
Unknown & $11(20.8)$ & $2(11.1)$ & $9(32.1)$ \\
RRT & $12(22.6)$ & $1(5.6)$ & $9(32.1)$ \\
\hline
\end{tabular}

Abbreviations: AKI, acute kidney injury; COVID-19, coronavirus disease 2019; KTR, kidney transplant recipients; RRT, renal replacement therapy.

${ }^{\text {a }}$ The outcome of AKI was classified as resolved if serum creatinine return to within 1.5 times baseline and is less than $0.3 \mathrm{mg} / \mathrm{dl}(26.5 \mathrm{mmol} / \mathrm{l})$ increase from baseline and ongoing if serum creatinine does not return to that range.

\section{DISCUSSION}

Our study suggests KTR are very likely to develop severe COVID-19 during hospitalization who require ICU admission or mechanical ventilation or develop severe complications such as respiratory failure. $47.4 \%$ patients were classified into the non-severe group and $52.6 \%$ into the severe group.

Time from transplant is associate with the severity and mortality of COVID-19 in this population. The median age (59 vs 50 years) and the median time from transplant ( 8.3 vs 4.5 years) of the severe patients was larger compared with those non-severe (table 1). Our study does not support the hypothesis that KTR may have increased risk of developing severe disease with viral infection within the first few months due to intensive immunosuppressive therapy and early complication of transplant. Only 1 of 8 patients died within the first 6 months after transplant. The current study indicates KTR with longer time from transplantation is more vulnerable with COVID-19.

Majority of KTR have at least one comorbidity. Since end stage renal disease is often caused by hypertension or diabetes, KTR appear to have higher prevalence of comorbidities than the general population. This would result in the increased risk of developing severe disease and poor prognosis during COVID-19. CVD is a common morbidity in our study. Research found patients with severe COVID-19 exhibited significantly elevated high-sensitivity cardiac troponin I which indicates myocardial injury caused by viral infection ${ }^{51}$. 
The symptoms of COVID-19 are nonspecific in KTR compared to the general population. Main clinical symptoms were similar between severe and non-severe KTR except dyspnea. Severe patients were more likely to present with dyspnea (70.3\% vs $40.0 \%$ ) on admission, were diagnosed with COVID-19 (mean days from symptom onset, 6 vs 8 days) and admitted to hospital (mean days from symptom onset, 5 vs 7 days) earlier than the non-severe patients. Immunocompromised status may alter clinical symptoms and courses of COVID-19. Several studies $^{15,30,33,40}$ reported patients had the sudden onset of the severe symptom of dyspnea on admission without any other common COVID-19 symptoms. The lack of common symptoms may lead to delayed diagnosis and poor prognosis. Clinicians need to be prepared to monitor and treat solid organ transplant recipients with sudden onset of severe COVID-19.

The mean values of the inflammatory biomarkers and kidney function had beyond the normal clinical range. They could be used to estimate the severity of COVID-19. Lymphopenia is very common in patients with COVID-19 and a study found low blood lymphocyte percentage could be used as a predictor of severe COVID-19 ${ }^{52}$. Those who died often exhibited the blood lymphocyte percentage lower than $5 \%$ within 2 weeks after symptom onset ${ }^{52}$, while when patients recover, their lymphocyte count significantly increased ${ }^{19}$. D-dimer is another important biomarker for mortality. The D-dimer less than $2.0 \mu \mathrm{g} / \mathrm{mL}$ on admission often predicts in-hospital death in patients with COVID- $19^{53}$.

We found the mortality of KTR with COVID-19 requiring hospitalization is high. The overall mortality is $20.3 \%$ and the mortality is $30.8 \%$ among those discharged alive and dead (table 2). Several studies have reported the mortality ranging from $5.8 \%$ to $17.1 \%$ in the discharged general COVID-19 positive population ${ }^{54-56}$. Also, the mortality of the discharged patients in our review is higher than in Lubetzky et al study which reported a mortality of $12.0 \%$ in 39 hospitalized KTR infected with COVID-19 in New York ${ }^{49}$. The high prevalence of underlying kidney disorders, existing co-morbidities such as diabetes and hypertension, the complications related to kidney transplant and the side effects of immunosuppressive medication in kidney transplant population may contribute to the extra mortality.

With further analysis, an obvious discrepancy in mortality between different countries has been observed in our study (table 3). The mortality of different countries ranged from $10.5 \%$ to $69.2 \%$. Whether it is caused by different admission criteria, demography of the population or the management guidelines for KTR with COVID-19 in different countries is unclear. Future research is warranted to investigate it for identifying the optimal treatment option.

Additionally, although advanced age is associated with the severe COVID-19 and high mortality in our study population, young immunosuppressed KTR is also vulnerable to COVID-19. The mortality rate by 10 -year age intervals was demonstrated in the table 4 and it was noted that $41.4 \%$ of those who died were less than 60 years of age. Our research indicates 
a higher proportion of younger KTR could develop severe COVID-19 and die compared to the general population.

Two patients were readmitted to hospital due to recurrence of symptoms within 48 hours from discharge, with one discharged alive again after 7 days of hospitalization and another staying in hospital with new-onset consolidations on the chest X-ray. Additionally, 6 KTR were reported to be confirmed with bacterial co-infection during hospitalization with COVID-19. Although KTR are commonly expected to suffer from bacterial co-infection with hospitalization due to their long-term immunosuppressed status, patients in our studies does not demonstrated the elevated risk of bacterial co-infection.

Our study indicates a large proportion of in-hospital KTR developed severe COVID-19 and the clinical outcome is dire if they need ICU admission or mechanical ventilation (table 2). $52.6 \%$ of patients developed severe COVID-19 according to our criteria. The mortality of those with ICU admission is $53.3 \%$. The mortality $(73.3 \%$ vs $38.5 \%)$ is significantly higher in patients requiring IV compared to those only requiring NIV.

Furthermore, this review indicates that a higher proportion of KTR (47.3\%) with COVID-19 develop acute kidney injury during hospitalization compared to the general COVID-19 population (table 5). The studies with a large number of general COVID-19 population reported the rates of AKI from $11.0 \%{ }^{57}$ to $36.6 \%{ }^{58}$. Additionally, we found severe patients are more likely to experience AKI (54.9\% vs $39.1 \%$ ), less likely to resolve it (10.7\% vs $77.8 \%$ ) and more frequently require renal replacement therapy (32.1\% vs 5.6\%) compared to non-severe patients. Several studies have explored the potential mechanisms of the development of AKI during COVID-19, such as the cytopathic effects of COVID-19 on proximal straight tubule cells ${ }^{59}$, the occlusion of microvascular lumens, the glomerular and vascular damage and direct kidney parenchyma infection of SARS-CoV- $2^{60}$. Also, underlying kidney disorders of KTR and the nephrotoxicity of immunosuppressive and antiviral drugs may be related to the high prevalence of AKI in this population. Finally, when clinicians make treatment plans for KTR, they need to balance between the uncertain benefit of antiviral drugs and their side effects which may lead to acute kidney injury. Lopinavir, for example, can disturb the metabolism of tacrolimus ${ }^{61}$. Several included studies reported significantly elevated tacrolimus trough levels in KTR with COVID-19 after using lopinavir and/or ritonavir ${ }^{26,29,45,47}$. One patient in our review developed tacrolimus-induced nephrotoxicity when using lopinavir/ritonavir therapy and needed renal replacement therapy ${ }^{29}$. Tacrolimus trough levels should be monitored closely in COVID-19 positive KTR with hospitalization.

\section{Limitations}

The main limitation is missing data of the included studies. Secondly, the methodological quality of eligible studies is diverse and their reporting bias cannot be ruled out. Future studies 
with large sample size and intact data of patients' clinical characteristics and courses are warranted.

\section{CONCLUSION}

Although the symptoms of in-hospital kidney transplant recipients with COVID-19 are nonspecific, they are at high risk of developing severe disease at a relatively young age. They have higher mortality and the higher prevalence of acute kidney injury compared to the general population with COVDI-19. The outcome of acute kidney injury is poor in kidney transplant recipients with severe COVID-19.

\section{AUTHOR CONTRIBUTIONS}

Conceptualization, methodology, data extraction and curation, Y.S. and S.T.; software, formal analysis, investigation, writing original draft preparation, Y.S.; writing review and editing, Y.S. and S.T. All authors have read and agreed to the published version of the manuscript.

\section{REFERENCE}

1. Johns Hopkins Coronavirus Resource Center. COVID-19 Map. 2020. Available at: https://coronavirus.jhu.edu/map.html, accessed July 10, 2020

2. Sohrabi C, Alsafi Z, O'Neill N, et al. World Health Organization declares global emergency: A review of the 2019 novel coronavirus (COVID-19) [published correction appears in Int J Surg. 2020 May;77:217]. Int J Surg. 2020;76:71-76. doi:10.1016/j.ijsu.2020.02.034

3. Zhou F, Yu T, Du R, et al. Clinical course and risk factors for mortality of adult inpatients with COVID-19 in Wuhan, China: a retrospective cohort study. Lancet. 2020;395(10229):1054-1062. doi:10.1016/S0140-6736(20)30566-3

4. Zhang M, Zhang J, Shi H, et al. Viral shedding prolongation in a kidney transplant patient with COVID-19 pneumonia [published online ahead of print, 2020 May 13]. Am J Transplant. 2020;10.1111/ajt.15996. doi:10.1111/ajt.15996

5. Kunisaki KM, Janoff EN. Influenza in immunosuppressed populations: a review of infection frequency, morbidity, mortality, and vaccine responses. Lancet Infect Dis. 2009;9(8):493-504. doi:10.1016/S1473-3099(09)70175-6

6. Zhang $\mathrm{C}, \mathrm{Wu} \mathrm{Z}, \mathrm{Li} \mathrm{JW}$, et al. Cytokine release syndrome in severe COVID-19: interleukin-6 receptor antagonist tocilizumab may be the key to reduce mortality. Int $J$ Antimicrob Agents. 2020;55(5):105954. doi:10.1016/j.ijantimicag.2020.105954

7. Hirano T, Murakami M. COVID-19: A New Virus, but a Familiar Receptor and Cytokine Release Syndrome. Immunity. 2020;52(5):731-733. doi:10.1016/j.immuni.2020.04.003

8. Ruan Q, Yang K, Wang W, et al. Clinical predictors of mortality due to COVID-19 
based on an analysis of data of 150 patients from Wuhan, China. Intensive Care Med. 2020;46(5):846-848. doi:10.1007/s00134-020-05991-x

9. Keller CA. Solid Organ Transplantation Overview and Selection Criteria. Am J Manag Care. 2015;21(1 Suppl):S4-S11.

10. Liberati A, Altman DG, Tetzlaff J, et al. The PRISMA statement for reporting systematic reviews and meta-analyses of studies that evaluate healthcare interventions: explanation and elaboration. BMJ. 2009;339. doi:10.1136/bmj.b2700

11. Gagnier JJ, Kienle G, Altman DG, et al. The CARE Guidelines: Consensus- Based Clinical Case Reporting Guideline Development. Headache J Head Face Pain. 2013;53(10):1541-1547.

12. National Health Commission. Diagnosis and Treatment Protocol for Novel Coronavirus Pneumonia (Trial Version 7). 2020. Available at: https://www.chinadaily.com.cn/pdf/2020/1.Clinical.Protocols.for.the.Diagnosis.and.T reatment.of.COVID-19.V7.pdf, accessed July 12, 2020

13. Kellum JA, Lameire N, Aspelin P, et al. Kidney disease: Improving global outcomes (KDIGO) acute kidney injury work group. KDIGO clinical practice guideline for acute kidney injury. Kidney Int Suppl. 2012;2(1):1-138. doi:10.1038/kisup.2012.1

14. Kocak B, Arpali E, Akyollu B, et al. A Case Report of Oligosymptomatic Kidney Transplant Patients with COVID-19: Do They Pose a Risk to Other Recipients? [published online ahead of print, 2020 May 15]. Transplant Proc. 2020;10.1016/j.transproceed.2020.05.028. doi:10.1016/j.transproceed.2020.05.028

15. Billah M, Santeusanio A, Delaney V, et al. A catabolic state in a kidney transplant recipient with COVID-19 [published online ahead of print, 2020 May 1]. Transpl Int. 2020;10.1111/tri.13635. doi:10.1111/tri.13635

16. Chen S, Yin Q, Shi H, et al. A familial cluster, including a kidney transplant recipient, of Coronavirus Disease 2019 (COVID-19) in Wuhan, China. Am J Transplant. 2020; 20: 1869- 1874. https://doi.org/10.1111/ajt.15903

17. Alberici F, Delbarba E, Manenti C, et al. A single center observational study of the clinical characteristics and short-term outcome of 20 kidney transplant patients admitted for SARS-CoV2 pneumonia. Kidney Int. 2020;97(6):1083-1088. doi:https://dx.doi.org/10.1016/j.kint.2020.04.002

18. Guillen E, Pineiro GJ, Revuelta I, et al. Case report of COVID-19 in a kidney transplant recipient: Does immunosuppression alter the clinical presentation?. Am J Transplant. 2020;20(7):1875-1878. doi:10.1111/ajt.15874

19. Mella A, Mingozzi S, Gallo E, et al. Case series of six kidney transplanted patients with COVID-19 pneumonia treated with tocilizumab [published online ahead of print, 2020 
Jun 5]. Transpl Infect Dis. 2020;e13348. doi:10.1111/tid.13348

20. Zhong, Z, Zhang, Q, Xia, H, et al. Clinical characteristics and immunosuppressants management of coronavirus disease 2019 in solid organ transplant recipients. Am J Transplant. 2020; 20: 1916- 1921. https://doi.org/10.1111/ajt.15928

21. Abrishami A, Samavat S, Behnam B, et al. Clinical Course, Imaging Features, and Outcomes of COVID-19 in Kidney Transplant Recipients. Eur Urol. 2020;78(2):281286. doi:10.1016/j.eururo.2020.04.064

22. Fung M, Chiu CY, DeVoe C, et al. Clinical outcomes and serologic response in solid organ transplant recipients with COVID-19: A case series from the United States. Am J Transplant. 2020; 00: 1-9. https://doi.org/10.1111/ajt.16079

23. Cheng DR, Wen JQ, Liu ZZ, et al. Coronavirus disease 2019 in renal transplant recipients: report of two cases [published online ahead of print, 2020 May 16]. Transpl Infect Dis. 2020;e13329. doi:10.1111/tid.13329

24. Zhu L, Gong N, Liu B, et al. Coronavirus Disease 2019 Pneumonia in Immunosuppressed Renal Transplant Recipients: A Summary of 10 Confirmed Cases in Wuhan, China. Eur Urol. 2020;77(6):748-754. doi:https://dx.doi.org/10.1016/j.eururo.2020.03.039

25. Wang J, Li X, Cao G, Wu X, et al. COVID-19 in a kidney transplant patient. Eur Urol. 2020;77(6):769.

26. Gandolfini I, Delsante M, Fiaccadori E, et al. (2020), COVID-19 in kidney transplant recipients. Am J Transplant, 20: 1941-1943. doi:10.1111/ajt.15891

27. Nair V, Jandovitz N, Hirsch JS, et al. COVID-19 in kidney transplant recipients. Am J Transplant. 2020; 20: 1819-1825. https://doi.org/10.1111/ajt.15967

28. Huang J, Lin $\mathrm{H}, \mathrm{Wu} \mathrm{Y}$, et al. COVID-19 in posttransplant patients-report of 2 cases. Am J Transplant. 2020; 20: 1879- 1881. https://doi.org/10.1111/ajt.15896

29. Fernández-Ruiz M, Andrés A, Loinaz C, et al. COVID-19 in solid organ transplant recipients: A single-center case series from Spain. Am J Transplant. 2020;20(7):18491858. doi:10.1111/ajt.15929

30. Banerjee D, Popoola J, Shah S, et al. COVID-19 infection in kidney transplant recipients. Kidney Int. 2020;97(6):1076-1082. doi:http://dx.doi.org/10.1016/j.kint.2020.03.018

31. Fontana F, Alfano G, Mori G, et al. COVID-19 pneumonia in a kidney transplant recipient successfully treated with tocilizumab and hydroxychloroquine. Am $J$ Transplant. 2020; 20: 1902- 1906. https://doi.org/10.1111/ajt.15935

32. Kates, OS, Fisher, CE, Stankiewicz-Karita, HC, et al. Earliest cases of coronavirus disease 2019 (COVID-19) identified in solid organ transplant recipients in the United 
States. Am J Transplant. 2020; 20: 1885- 1890. https://doi.org/10.1111/ajt.15944

33. The Columbia University Kidney Transplant Program. Early Description of Coronavirus 2019 Disease in Kidney Transplant Recipients in New York. J Am Soc Nephrol. 2020;31(6):1150-1156. doi:https://dx.doi.org/10.1681/ASN.2020030375

34. Marx D, Moulin B, Fafi-Kremer S, et al. First case of COVID-19 in a kidney transplant recipient treated with belatacept. Am J Transplant. 2020;20(7):1944-1946. doi:10.1111/ajt.15919

35. Zhang H, Chen Y, Yuan Q, et al. Identification of Kidney Transplant Recipients with Coronavirus Disease 2019. Eur Urol. 2020;77(6):742-747. doi:https://dx.doi.org/10.1016/j.eururo.2020.03.030

36. Bussalino, E, De Maria, A, Russo, R, Paoletti, E. Immunosuppressive therapy maintenance in a kidney transplant recipient with SARS-CoV-2 pneumonia: A case report. Am J Transplant. 2020; 20: 1922- 1924. https://doi.org/10.1111/ajt.15920

37. Allam SR, Dao A, Madhrira MM, et al. Interleukin-6 receptor antagonist therapy to treat SARS-CoV-2 driven inflammatory syndrome in a kidney transplant recipient [published online ahead of print, 2020 May 14]. Transpl Infect Dis. 2020;e13326. doi:10.1111/tid.13326

38. Namazee N, Mahmoudi H, Afzal P, et al. Novel Corona Virus 2019 pneumonia in a kidney transplant recipient. Am

Transplant. 2020; 00: 1- 3. https://doi.org/10.1111/ajt.15999

39. Ning L, Liu L, Li W, et al. Novel coronavirus (SARS-CoV-2) infection in a renal $\begin{array}{llll}\text { transplant } & \text { recipient: } & \text { Case } & \text { report. } A m\end{array}$ Transplant. 2020; 20: 1864- 1868. https://doi.org/10.1111/ajt.15897

40. Gautier-Vargas G, Baldacini C, Benotmane I, et al. Rapid resolution of cytokine release syndrome and favorable clinical course of severe COVID-19 in a kidney transplant recipient treated with tocilizumab. Kidney Int. 2020;98(2):508-509. doi:10.1016/j.kint.2020.05.022

41. Seminari E, Colaneri M, Sambo M, et al. The COVID19 IRCCS San Matteo Pavia Task Force. SARS Cov-2 infection in a renal-transplanted patients. A case report. Am J Transplant. 2020; 20: 1882- 1884. https://doi.org/10.1111/ajt.15902

42. Meziyerh S, Zwart TC, van Etten RW, et al. Severe COVID-19 in a renal transplant recipient: A focus on pharmacokinetics. Am J Transplant. 2020; 20: 1896- 1901. https://doi.org/10.1111/ajt.15943

43. Lauterio A, Valsecchi M, Santambrogio S, et al. Successful recovery from severe COVID-19 pneumonia after kidney transplantation: The interplay between immunosuppression and novel therapy including tocilizumab [published online ahead 
of print, 2020 May 25]. Transpl Infect Dis. 2020;e13334. doi:10.1111/tid.13334

44. Zhu L, Xu X, Ma K, et al. Successful recovery of COVID-19 pneumonia in a renal transplant recipient with long-term immunosuppression. Am $J$ Transplant. 2020;20(7):1859-1863. doi:10.1111/ajt.15869

45. Bartiromo M, Borchi B, Botta A, et al. Threatening drug-drug interaction in a kidney transplant patient with coronavirus disease 2019 (COVID-19) [published online ahead of print, 2020 Apr 12]. Transpl Infect Dis. 2020;e13286. doi:10.1111/tid.13286

46. Faguer S, Del Bello A, Abravanel F, et al. Tocilizumab for Hemophagocytic Syndrome in a Kidney Transplant Recipient With COVID-19. Ann Intern Med. Available at: doi:https://dx.doi.org/10.7326/L20-0419, accessed July 18, 2020

47. Kim, Y, Kwon, O, Paek, JH, et al. Two distinct cases with COVID-19 in kidney transplant recipients. Am

Transplant. 2020; 00: 1- 7. https://doi.org/10.1111/ajt.15947

48. Akalin E, Azzi Y, Bartash R, et al. Covid-19 and Kidney Transplantation. N Engl J Med. 2020;382(25):2475-2477. doi:10.1056/NEJMc2011117

49. Lubetzky M, Aull MJ, Craig-Schapiro R, et al. Kidney allograft recipients, immunosuppression, and coronavirus disease-2019: a report of consecutive cases from a New York City transplant center [published online ahead of print, $2020 \mathrm{Jul}$ 17]. Nephrol Dial Transplant. 2020;gfaa154. doi:10.1093/ndt/gfaa154

50. Trujillo H, Caravaca-Fontán F, Sevillano Á, et al. SARS-CoV-2 Infection in Hospitalized Patients with Kidney Disease [published online ahead of print, 2020 May 1]. Kidney Int Rep. 2020;5(6):905-909. doi:10.1016/j.ekir.2020.04.024

51. Wang D, Hu B, Hu C, et al. Clinical characteristics of 138 hospitalized patients with 2019 novel coronavirus-infected pneumonia in Wuhan, China. Jama. 2020; 17;323(11):1061-9.

52. Tan L, Wang Q, Zhang D et al. Lymphopenia predicts disease severity of COVID-19: a descriptive and predictive study. Sig Transduct Target Ther 5,33 (2020). https://doi.org/10.1038/s41392-020-0148-4

53. Zhang L, Yan X, Fan Q, et al. D-dimer levels on admission to predict in-hospital mortality in patients with Covid-19. J Thromb Haemost. 2020;18(6):1324-1329. doi:10.1111/jth.14859

54. Gold JAW, Wong KK, Szablewski CM, et al. Characteristics and Clinical Outcomes of Adult Patients Hospitalized with COVID-19 — Georgia, March 2020. MMWR Morb Mortal Wkly Rep. 2020;69(18):545-550. doi:10.15585/mmwr.mm6918e1

55. Myers LC, Parodi SM, Escobar GJ, et al. Characteristics of Hospitalized Adults with COVID-19 in an Integrated Health Care System in California. JAMA. 
2020;323(21):2195-2198. doi:10.1001/jama.2020.7202

56. Mehra MR, Desai SS, Kuy S, et al. Cardiovascular Disease, Drug Therapy, and Mortality in Covid-19. N Engl J Med. 2020;382(25):e102. doi:10.1056/NEJMoa2007621

57. Kunutsor SK, Laukkanen JA. Renal complications in COVID-19: a systematic review and meta-analysis. Annals of Medicine, 2020. Available at: https://www.tandfonline.com/doi/full/10.1080/07853890.2020.1790643?scroll=top\&n eedAccess=true, accessed July 18,2020

58. Hirsch JS, Ng JH, Ross DW, et al. Acute kidney injury in patients hospitalized with COVID-19. Kidney Int. 2020; 98, 209-218

59. Pan XW, Xu D, Zhang H, et al. Identification of a potential mechanism of acute kidney injury during the COVID-19 outbreak: a study based on single-cell transcriptome analysis. Intensive Care Med. 2020;46(6):1114-1116. doi:10.1007/s00134-020-060261

60. Su H, Yang M, Wan C, et al. Renal histopathological analysis of 26 postmortem findings of patients with COVID-19 in China. Kidney Int. 2020;98(1):219-227. doi:10.1016/j.kint.2020.04.003

61. Kumar GN, Dykstra J, Roberts EM, et al. Potent inhibition of the cytochrome P-450 3A-mediated human liver microsomal metabolism of a novel HIV protease inhibitor by ritonavir: A positive drug-drug interaction. Drug Metab Dispos. 1999;27(8):902-908.lu

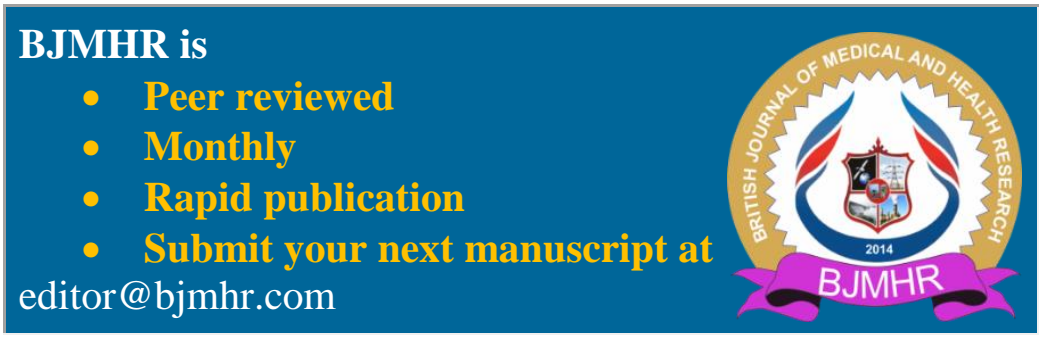

